https://doi.org/10.22498/pages.25.2.80

\title{
Entangled ecosystem-people-animal interactions: perspectives from the East African savannas
}

\author{
Rob Marchant, C. Courtney-Mustaphi and E. Githumbi
}

Under current rapid environmental change there are numerous challenges for people and wildlife. Paleoecological records from southern Kenya are synthesized to provide understanding on how abiotic and biotic elements intertwine and can provide a foundation to inform decisions for environmental management.

\begin{abstract}
Abiotic and biotic elements intertwine over multiple spatio-temporal scales to determine the present-day composition, structure and distribution of ecosystems. Rapid compositional and distributional changes, particularly during the past few hundred years, are attributed to anthropogenic modifications that are superimposed on long-term climatic and landscape changes (Dearing et al. 2010). It is crucial to have a paleo perspective to disentangle interactions of how the environment, ecosystems, animals and people have combined to influence current ecosystem states, and to learn how lessons from the past can be used to predict and constrain possible future trajectories (Marchant and Lane 2014).
\end{abstract}

The savanna ecosystems of East Africa are characterized by relatively rapid population growth, changing political, economic, social and cultural contexts, and an agricultural system that is increasingly focused on relatively recently adopted crops, such as maize and market gardening, for regional and international export. This expansion and intensification of agriculture across East African savannas induces particularly rapid land-use and land-cover change. East African savannas also support large human and herbivore populations and have become frontiers for water-intensive agricultural expansion on communal lands formerly dedicated to livestock grazing. Balancing economic development while maintaining ecosystem integrity and the globally important protected area creates policy challenges, which are further exacerbated by climate change. The traditionally reliable dry and rainy seasons have been increasingly disrupted and the unpredictability of the rainy season has become the norm for many savanna communities. Government policies that have encouraged formerly mobile herders to adopt more settled ways of life for both positive (health, education) and negative (land grab, containment) reasons, combined with land fragmentation and degradation, hamper the adaptive ability of communities to respond to inherent climatic variability, for example through transhumance pastoralism. Increasingly intensive land uses, often focused around Protected Area boundaries (Pfeifer et al. 2012), similarly pose threats and challenges for ecosystems, conservation and livelihoods. While there have been numerous calls to address such challenges, current intervention strategies have had limited success, as evidenced by continued encroachment, human-wildlife conflict and the rise of poaching and illegal hunting, along with unabated rapid agricultural development and associated pressure on water resources. These changes are leading to (wildlife) habitat degradation, increased fragmentation of populations, decreased resilience, and biodiversity loss across much of the East African savannas.

One area where these transformations have been acutely felt is within the Amboseli landscape, an area that is somewhat symptomatic of the wider Kenya Tanzanian borderland area (Fig. 1). The Amboseli landscape supports the highest wildlife densities in southern Kenya that migrates across the Kenyan and Tanzanian border. Within the Amboseli landscape there are several perennial wetlands distributed across the predominantly semi-arid landscape; these groundwater-fed wetlands, recharged from orographic precipitation falling on Mount Kilimanjaro (Fig. 2), provide an important source of water and wildlife refuge, and form a series of "stepping stones" for animal migrations between Amboseli National Park and the neighboring Tsavo and Chyulu Hills National Parks (Fig. 1). Unlike seasonally rain-fed wetlands, which are inundated during the wet season and dry out during the dry season, the Amboseli wetlands sustain perennially high local water-tables that enable peat accumulation through drought periods and hence form a paleoecological archive. Reconstruction of the vegetation, climatic and fire histories has been carried out on five of these swamps through pollen, non-pollen palynomorph and macroscopic charcoal analysis, which combine to produce a landscape scale understanding of ecosystem transitions and unpick the drivers behind these shifts. From the mid Holocene, East Africa shifted towards a drier environment characterized by reduced precipitation, increased evaporation, and/or an extension or intensification of the dry season. This period of regional aridity is clearly marked by a peak in aeolian dust deposition

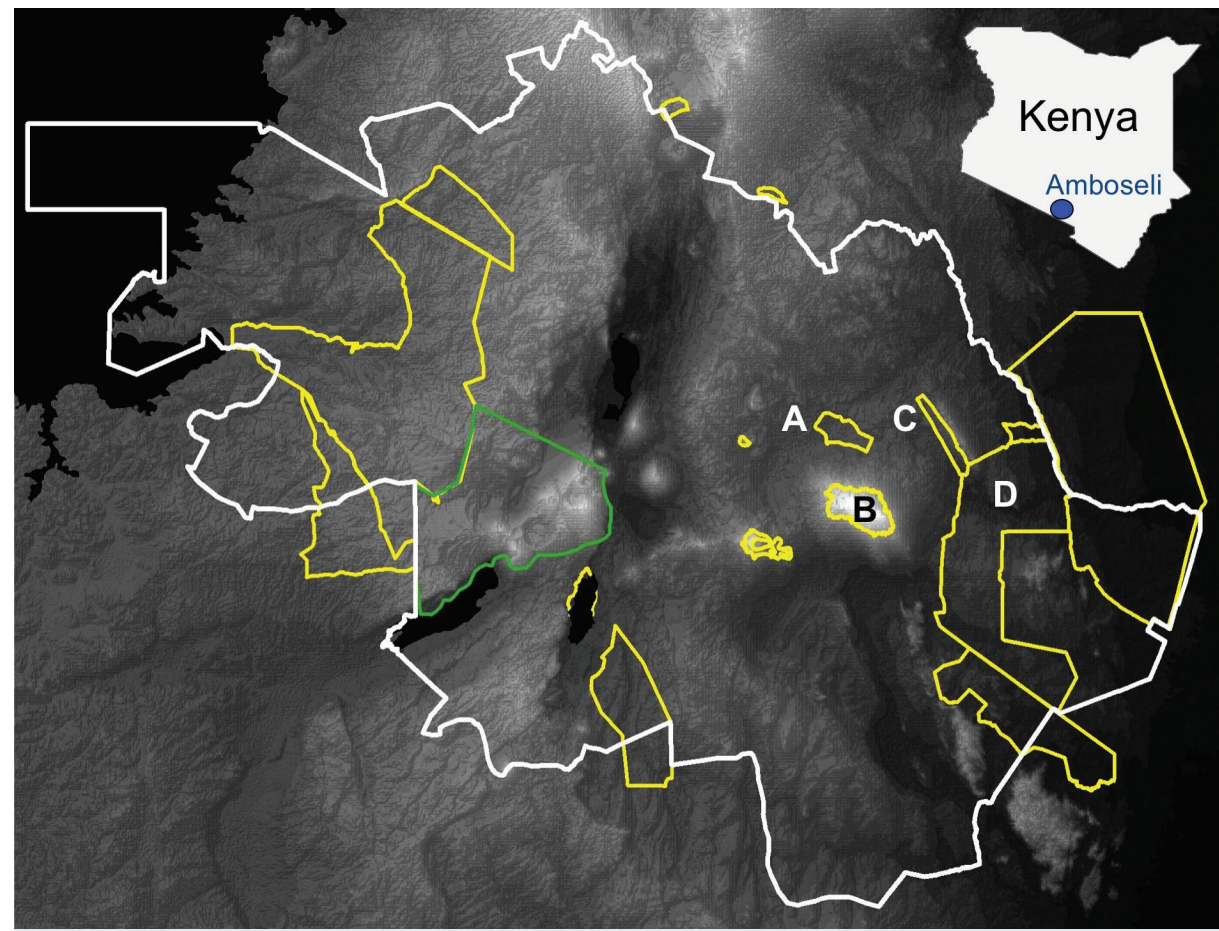

Figure 1: Map of the Kenya-Tanzania Borderlands within the white lines showing the outline locations of the National Parks (yellow) and the Ngorogoro Conservation Area (green). The protected areas (yellow) that surround the Amboseli National Park (A) are Kilimanjaro (B), the Chyulu Hills (C) and Tsavo National Parks (D). 

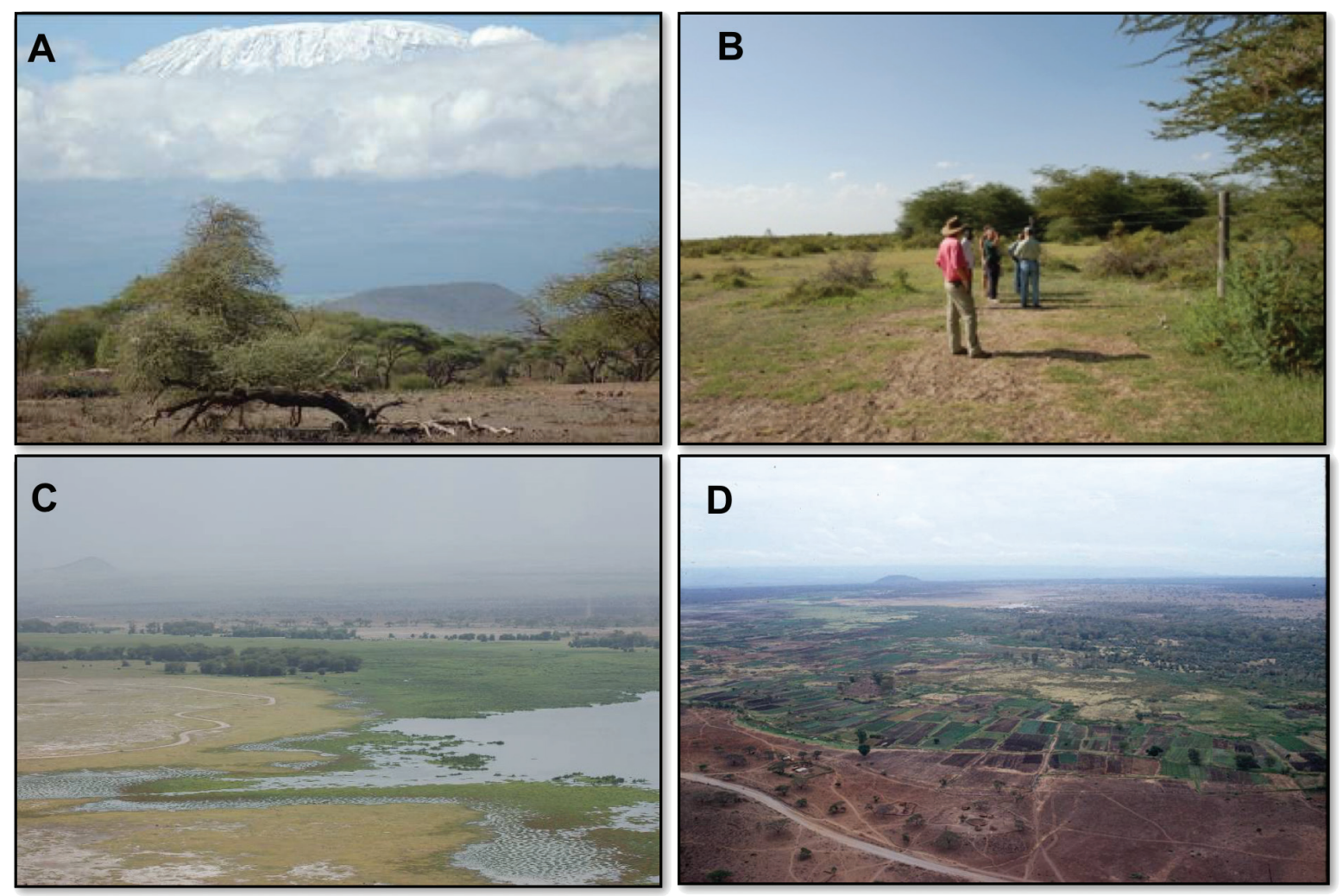

Figure 2: Different perspectives on Amboseli National Park. (A) The area is dominated by Mt Kilimanjaro; this is also the "water tower" that feeds the swamps with water to allow accumulation of sediments and the past ecosystem histories to be preserved. (B) Herbivores, particularly elephants, are crucially important ecosystem engineers across the landscape: the exclosure experiment clearly shows that with ca. seven years respite, a grazing lawn transitions into tree-dominated savanna (to the right of the fence). The wholescale removal of elephants from the East African landscape, particularly over the past four centuries, will have had a transformative impact on savanna structure and composition. (C and D) Current land-use transformations are similarly having a large impact on the swamps. Intact wetlands within the National Park boundaries (C) provide a grazing resource, particularly vital during dry seasons that are becoming increasingly severe and prolonged. They are a stark contrast to wetlands just outside the protected area that are drained and converted to agricultural production (D).

within the Kilimanjaro glacier dated to around $4000 \mathrm{cal}$ yr BP (Thompson et al. 2002). Under these relatively arid conditions, the Amboseli ecosystems were dominated by semi-arid taxa (Acacia, Aloe, AmaranthaceaeChenopodiaceae, Asteraceae and Capparis). Low charcoal concentrations due to low fuel availability show further evidence of the sparsely vegetated nature of the Amboseli landscape. Between $\sim 2000$ and 800 cal yr BP, there is an increase in pollen diversity as the savanna ecosystem became more dominated by woodland taxa (Acalypha, Balanites, Commiphora, Cordia and Salvadora), and aquatic taxa (Cyperaceae and Nymphaea) became locally more abundant. Increased abundance of wind-blown Afromontane forest taxa (Celtis, Juniperus and Olea), most likely derived from the adjacent slopes of Mount Kilimanjaro and the Chyulu Hills, further suggests a period of increased moisture that was concomitant with increased local biomass burning. After c. 800 cal yr BP, a drier environment returns with the increased presence of Amaranthaceae and Poaceae and decreased levels of mesic tree taxa such as Syzygium (Rucina et al. 2009), again with a regional expression of lower lake levels (Lamb et al. 2003; Westerberg et al. 2010).

Increased presence of Acacia, Amaranthaceae/Chenopdiaceae, Balanites and

Poaceae in the uppermost samples dating to the last ca. 300 years could be indicative of a drier environment, but could also be a consequence of decreased elephant populations which have a major influence on vegetation composition, distribution and structure
(Håkansson 2004; Fig. 2). Regional records, for example from Mt. Shengena located to the south of Amboseli in the Eastern Arc Mountains, reflect increased anthropogenic use of the landscape through the appearance and increased abundance of cultivated taxa such as Maize (Zea mays), Castor oil bean (Ricinus) and Pine (Pinus) to meet the needs of a growing and mobile population (Finch et al. 2016). Moreover, caravan trade resulted in the decimation of East African elephant populations (Håkansson 2004) that clearly would have been transformative for forest cover (Fig. 2). Anthropogenic modifications to the ecosystem have intensified dramatically in recent decades. Wetland areas were converted into agricultural production (shambas and commercial farming) as marked by the influx of crops and ruderal taxa (Fig. 2). Pastoralist populations with historical formal and informal land tenure have recently reorganized into more sedentary group ranches where some groups and individuals maintain pastoral livelihoods on an increasingly fragmented landscape. People have also migrated into the region and the increased population has placed additional demands on the Amboseli wetlands, clearly affecting socio-ecological resilience and wider ecosystem functioning of the landscape through the past ca. 4000 years.

It is clear from the Amboseli case study that long-term paleo perspectives provide understanding of the interactions between environment, ecosystems, animals and people, and as such provide a foundation to inform sustainable environmental management decisions (Gillson and Marchant 2014). Understanding how best to manage ecological systems, to protect biodiversity and benefit the human communities that rely on them, requires an interdisciplinary approach; this management is strengthened where paleo perspectives combine with social sciences and humanities to examine complex socio-ecological systems. To strengthen adaptive capacity, and promote resilience, it is crucial to understand how past and present socio-ecological systems are interlinked. Such insights are crucial to inform planning and practice, and inform longer-term planning frameworks such as the UN Sustainable Development Goals.

\section{AFFILIATIONS}

York Institute for Tropical Ecosystems, University of York, UK

\section{CONTACT}

Rob Marchant: robert.marchant@york.ac.uk

\section{REFERENCES}

\section{Dearing JA et al. (2010) Ecol Soc 15: 21}

Finch J et al. (2016) Holocene 27: 796-810

Gillson L, Marchant R (2014) Trends Ecol Evolut 29: 317-325

Håkansson N (2004) Hum Ecol 32: 561-591

Lamb H et al. (2003) Holocene 13: 285-292

Marchant R, Lane P (2014) J Arch Sci 51: 12-21

Pfeifer M et al. (2012) PloS One 7: e39337

Rucina SM et al. (2010) Holocene 20: 667-677

Thompson LG et al. (2002) Science 298: 589-593

Westerberg LO et al. (2010) Geogr J. 176: 304-318 